\title{
Are "tomorrow's doctors" honest? Questionnaire study exploring medical students' attitudes and reported behaviour on academic misconduct
}

\author{
S C Rennie, J R Crosby
}

Editorial by Glick and Letters p 296

Dundee University Medical School,

Curriculum Office, Ninewells Hospital and Medical School, Dundee DD1 9SY

S C Rennie

final year medical student

J R Crosby curriculum facilitator Correspondence to: J R Crosby

j.r.crosby@dundee. ac.uk

BMJ 2001;322:274-5

\section{bmj.com}

The survey used in this study appears on the BMJ's website
Honesty and integrity are key characteristics expected of a doctor, although academic misconduct among medical students is not new. ${ }^{1}$ A survey of 428 American students in 1980 found that $58 \%$ reported cheating during medical school. ${ }^{2}$ We assessed students' attitudes and behaviours on "cheating" and aimed to raise awareness of academic misconduct.

\section{Methods and results}

The survey was initiated, designed, and conducted by students. An anonymous questionnaire was distributed to 676 medical students in all years at Dundee medical school (only half of the fourth years were present at this time). The questionnaire was completed at the end of a lecture and collected by the main researcher (SCR). The questionnaire had 14 scenarios in which a fictitious student, "John," engaged in dishonest behaviour. Students were asked to give their gender, year, and views on informing faculty about misconduct and signing a written declaration.

For each scenario, students were asked whether they felt John was wrong and whether they had done or would consider doing the same. Responses were recorded "yes," "not sure," and "no" (students were not given the opportunity to distinguish between "have done" and "would consider doing"). Results were analysed with SPSS by using percentage frequency responses.

A total of 461 students $(68 \%)$ completed the questionnaire. Most students' attitude was that most of the scenarios were wrong. The exceptions were resubmitting work from a previous degree, chatting to a student about an objective structured clinical examination that one student has completed and the other is about to do, lending work to other students to look at, and copying text directly and simply listing the source in a reference list.

The proportion of students reporting that they had engaged in or would consider engaging in the scenarios varied from 2\% (95\% confidence interval $1-3 \%$ ) for copying answers in a degree examination to $56 \%(51-61 \%)$ for copying directly from published text and only listing it as a reference. About a third of students reported that they had engaged in or would consider engaging in the behaviour described in four of the scenarios: chatting about an objective structured clinical examination, writing "nervous system examination normal" when this hadn't been performed, lending work to others to look at, and copying text directly from published sources and simply listing the source in a reference list.

\section{Comment}

Students consider dishonest behaviour to be wrong and would not engage in it. However, that some
Attitudes and behaviours of students on scenarios involving academic misconduct (yes=wrong for attitudinal response; have done or would consider doing for behaviour response)

\begin{tabular}{|c|c|c|}
\hline Scenarios and responses & $\begin{array}{c}\text { Attitudes (\%) } \\
\text { (95\% CI) }\end{array}$ & $\begin{array}{c}\text { Behaviour (\%) } \\
(95 \% \mathrm{CI})\end{array}$ \\
\hline \multicolumn{3}{|c|}{$\begin{array}{l}\text { Forging a doctor's signature on a piece of work } \\
\text { s. }\end{array}$} \\
\hline Yes & 93 (91 to 95$)$ & $9(6$ to 12$)$ \\
\hline No & 3 (1 to 5$)$ & $83(80$ to 87$)$ \\
\hline Not sure & $4(2$ to 6$)$ & 9 (6 to 12$)$ \\
\hline \multicolumn{3}{|c|}{ Copying answers in degree examinations } \\
\hline Yes & 98 (97 to 99 ) & $2(1$ to 3$)$ \\
\hline No & $2(1$ to 3$)$ & 96 (94 to 98) \\
\hline Not sure & 0 & 2 (1 to 3$)$ \\
\hline \multicolumn{3}{|c|}{ Chatting to a student about an objective structured clinical examination } \\
\hline Yes & 43 (39 to 48$)$ & 30 (26 to 34$)$ \\
\hline No & 30 (26 to 34$)$ & 46 (41 to 51$)$ \\
\hline Not sure & 27 (23 to 31$)$ & 24 (20 to 28) \\
\hline \multicolumn{3}{|c|}{ Copying text directly and just including the source in reference list } \\
\hline Yes & $22(18$ to 26$)$ & 56 (51 to 61$)$ \\
\hline No & 57 (53 to 62$)$ & 25 (21 to 29$)$ \\
\hline Not sure & 21 (17 to 25$)$ & 19 (15 to 23 ) \\
\hline \multicolumn{3}{|c|}{ Copying text directly and not acknowledging the source } \\
\hline Yes & 82 (79 to 86$)$ & $14(11$ to 17$)$ \\
\hline No & 9 (6 to 12$)$ & 75 (71 to 79 ) \\
\hline Not sure & 9 (6 to 12$)$ & 11 (8 to 14$)$ \\
\hline \multicolumn{3}{|l|}{ Copying another student's work } \\
\hline Yes & 91 (88 to 94$)$ & $6(4$ to 8$)$ \\
\hline No & $6(4$ to 8$)$ & 84 (81 to 87 ) \\
\hline Not sure & $3(1$ to 5$)$ & 10 (7 to 13$)$ \\
\hline \multicolumn{3}{|c|}{ Lending work to other students to look at } \\
\hline Yes & $30(26$ to 34$)$ & 34 (30 to 38$)$ \\
\hline No & 61 (57 to 65$)$ & 51 (45 to 56 ) \\
\hline Not sure & 9 (6 to 12$)$ & 15 (12 to 18$)$ \\
\hline \multicolumn{3}{|c|}{ Lending work to other students to copy } \\
\hline Yes & 61 (57 to 66$)$ & 24 (20 to 28 ) \\
\hline No & $24(20$ to 28$)$ & 57 (52 to 62$)$ \\
\hline Not sure & 15 (12 to 18$)$ & 19 (15 to 23$)$ \\
\hline \multicolumn{3}{|c|}{ Writing a piece of work for another student } \\
\hline Yes & 82 (79 to 86$)$ & $9(6$ to 12$)$ \\
\hline No & 12 (9 to 15$)$ & 85 (82 to 88$)$ \\
\hline Not sure & $6(4$ to 8$)$ & $6(4$ to 8$)$ \\
\hline \multicolumn{3}{|c|}{ Writing "Nervous system-examination normal” when it hasn't been done } \\
\hline Yes & 75 (71 to 79$)$ & 32 (28 to 36 ) \\
\hline No & $14(11$ to 17$)$ & 56 (51 to 61$)$ \\
\hline Not sure & 11 (8 to 14$)$ & $12(9$ to 15$)$ \\
\hline \multicolumn{3}{|c|}{ Resubmitting work for another part of the course } \\
\hline Yes & $52(47$ to 57$)$ & 19 (15 to 23$)$ \\
\hline No & 30 (26 to 34$)$ & 65 (61 to 69$)$ \\
\hline Not sure & 18 (15 to 22$)$ & 16 (13 to 19$)$ \\
\hline \multicolumn{3}{|c|}{ Submitting a thesis from a previous degree for part of the course } \\
\hline Yes & 43 (39 to 48$)$ & 18 (14 to 22$)$ \\
\hline No & 37 (33 to 42$)$ & 63 (59 to 68$)$ \\
\hline Not sure & 20 (16 to 24$)$ & 19 (15 to 23$)$ \\
\hline \multicolumn{3}{|c|}{ Submitting a senior student's work as your own } \\
\hline Yes & 93 (91 to 95$)$ & 4 (2 to 6$)$ \\
\hline No & 5 (3 to 7$)$ & 93 (91 to 95) \\
\hline Not sure & $2(1$ to 3$)$ & $3(1$ to 5$)$ \\
\hline \multicolumn{3}{|c|}{ Submitting the same special study module report as another student } \\
\hline Yes & 65 (61 to 70$)$ & 4 (2 to 6$)$ \\
\hline No & $14(11$ to 17$)$ & 84 (81 to 87$)$ \\
\hline Not sure & 21 (17 to 25$)$ & 12 (9 to 15$)$ \\
\hline
\end{tabular}


students did report engaging in dishonest behaviour is seen as important and worrying. Fewer students consider it wrong to reference published text correctly compared with copying in exams, submitting a senior student's work, or copying another student's work. The responses for some of the scenarios involving plagiarism may indicate students' lack of understanding regarding referencing text appropriately and also a need for clear guidelines. Large proportions of students were also unsure whether exchanging information regarding an objective structured clinical examination was wrong. This may reflect confusion concerning the acceptability of swapping information and a lack of guidance given to students about appropriate behaviour.

Explaining to students what is acceptable behaviour is important when trying to reduce dishonesty. ${ }^{3}$ Shifting the emphasis from assessment to the learning process may result in a decrease in fraud and plagiarism. ${ }^{1}$ Academic misconduct is contrary to the ideals of academic and professional integrity and devalues the system of course assessment. It needs to be taken seriously by medical schools as it casts doubt on the validity of qualifications. ${ }^{5}$
We thank Professor D A Levison, dean of Dundee medical school, for supporting this study and proofreading our manuscripts; Professor I K Crombie, professor of epidemiology and public health, for his advice on the questionnaire design and statistical analysis of the results; Elizabeth Brown for her input into the questionnaire design; and the students of Dundee medical school for participating.

Contributors: SCR had the original idea and was the principal researcher, designing and distributing the questionnaire and doing the statistical analysis. JRC commented on the questionnaire and results. SCR and JRC designed the study, did the data entry and validation, and wrote the paper.JRC and SCR are the guarantors.

Funding: None.

Competing interests: None declared.

1 Anderson RE, Obenshain SS. Cheating by students: findings, reflections, and remedies. Acad Med 1994;69:323-32.

2 Sierles F, Hendrickx I, Circle S. Cheating in medical school. J Med Educ 1980;55:124-5.

3 Baldwin DC Jr, Daugherty SR, Rowley BD, Schwarz MD. Cheating in medical school: a survey of second-year students at 31 schools. Acad Med 1996;71:267-73

4 Wagner RF Jr. Medical student academic misconduct: implications of recent case law and possible institutional responses. Acad Med 1993:68:887-9.

5 Walker J. Students' plagiarism in universities: what are we doing about it? Higher Education Research and Development 1998;17:89-106.

(Accepted 18 September 2000)

\section{A book that changed my practice Problem oriented medical records}

As part of my senior registrar training at St Mary's in the late 1960 s I spent a year working on the cardiothoracic unit. It was while wrestling, both physically and mentally, with the two, three, or even four volumes of case notes of patients coming for cardiac surgery that I thought that there must be a better way of organising them.

Help was at hand. A film of one of Lawrence Weed's presentations was shown in the medical school. His vivid demonstration of what he thought of disorganised and confusing case notes caught my imagination. Why could doctors not use a scientific methodology when recording their clinical findings? I was seized with a missionary fervour and for 35 years used the principles of the problem oriented medical record (POMR) in my clinical and teaching practice. ${ }^{1}$

Weed pointed out that the features with which patients present could, by the application of an inquiring and trained mind, be designated as problems. These might be a symptom, a sign, an abnormal laboratory or radiological finding, a social burden or a previously diagnosed disorder. "Active" problems needed evaluation while all carers needed to be aware of the "inactive/resolved" ones. To identify all the problems history taking, physical examination, and investigations had to be defined and complete.

The type of clinical practice involved in the patient's care defines this database. Subjective data $(\boldsymbol{S})$ is compiled from the history, objective data $(\boldsymbol{O})$ from the physical examination and the results of any investigations. The assessment $(\boldsymbol{A})$ explains the identified problem in pathophysiological terms and the evaluation of each active problem concludes with a management plan $(\boldsymbol{P})$ of investigations $(D x)$ to confirm or rule out a condition, treatment $(R x)$, and education $(E)$. By placing the problem list at the front of the clinical record everyone involved in patient care can be aware of the list of active and inactive/resolved problems. Where appropriate the results of investigations and changes in clinical status are displayed on data summary sheets and flow sheets. Those responsible for changing a management plan use the mnemonic $S O A P$ to record their findings and reasons for so doing. Discharge summaries and letters to colleagues use the same format.

I found Weed's principles useful in teaching medical students the basics of clinical deduction, invaluable for demonstrating the importance of their clinical notes to pre-registration house officers, and an essential part of $\mathrm{SHO}$ and registrar training. My attempts to introduce POMR throughout my hospital were less successful. In later years as an assessor advising on clinical complaints, how I wished more doctors had heeded Weed's advice.

Did POMR improve patient care on my unit? I think it did and it was encouraging to see that the American Institute of Medicine thought so too. ${ }^{2}$ Have any of my trainees continued to use POMR in their clinical practice? I don't know-perhaps I ought to find out now that I have all this spare time.

Peter Savage consulting surgeon, Sidcup

1 Weed LL. Medical records, medical education, and patient care. The problem-oriented record as a basic tool. Cleveland, $\mathrm{OH}$ : Case Western Reserve University, 1969.

2 Institute of Medicine. The computer-based patient record: an essential technology for health care. Washington DC: National Academy Press, 1991.

We welcome articles of up to 600 words on topics such as A memorable patient, A paper that changed my practice, My most unfortunate mistake, or any other piece conveying instruction, pathos, or humour. If possible the article should be supplied on a disk. Permission is needed from the patient or a relative if an identifiable patient is referred to. We also welcome contributions for "Endpieces," consisting of quotations of up to 80 words (but most are considerably shorter) from any source, ancient or modern, which have appealed to the reader. 